\title{
IDENTIDADES, CONTINUIDADES Y RUPTURAS \\ EN EL CULTO AL AGUA Y A LOS CERROS EN SOCOROMA, UNA COMUNIDAD ANDINA DE LOS AlTOS DE ARICA
}

\author{
Carlos Choque y Elías Pizarro ${ }^{1}$
}

\section{* Introducción}

Resumen

En este artículo se muestran las rupturas y continuidades del culto al agua y los cerros en la comunidad andina de Socoroma (norte de Chile). Con ello buscamos identificar y comprender las expresiones rituales presentes en la tradición oral y en las manifestaciones religiosas de esta comunidad. Dichas expresiones constituyen un elemento fundamental para generar la identidad cultural de sus habitantes. Intentaremos mostrar cómo el culto a los cerros y al agua se reelaboran a partir de los procesos de cambio cultural, generando nuevas deconstrucciones en los ritos agrícolas.

Palabras claves: cerros sagrados - culto al agua - Socoroma norte de Chile - Andes Centro-Sur.

\begin{abstract}
This research shows the breaks and continuities evidence of the cult of water and mountains in the Andean community of Socoroma

(Northern Chile). We attempt to identify and understand the ritual expressions present in oral tradition and the religious manifestations of this community, which are fundamental elements in generating the cultural identity of its inhabitants. Our purpose is to show how the cult of the mountains and the water is reworked through the processes of cultural change, generating new deconstructions in agricultural rites.
\end{abstract}

Key words: sacred mountains - cult to water - Socoroma Northern Chile - South Central Andes.

Recibido: noviembre 2011. Aceptado: enero 2013.
La identidad y ritualidad de los aymara del norte de Chile han sido ampliamente estudiadas por varios autores (p.e., González 1997; Gundermann 2000, 2004, 2005; Van Kessel 2001, 2003a; Zapata 2007; Martínez 2009). No obstante, durante la última década, los trabajos etnográficos destinados al estudio del culto a los cerros, sus vinculaciones con ritos asociados al agua y su relación con la territorialidad sagrada son más bien escasos en el ámbito local, deficiencia que en esta oportunidad trataremos de superar. No obstante, el despoblamiento de los Altos de Arica es un factor negativo que nos priva de importantes testimonios sobre el tema en cuestión (Figura 1).

Los procesos de transformación socioculturales han sido vividos por la población aymara en la región desde la década de 1960 en adelante, provocando cambios sustanciales, ya que parte de ella dejó la agricultura y ganadería para convertirse en asalariada en las ciudades, relegando a una posición secundaria, y a la vez, olvidando, una serie de prácticas ceremoniales que en el pasado fueron parte esencial del calendario ritual de los habitantes de la comunidad andina de Socoroma ${ }^{2}$. Esta localidad se ubica a $3.200 \mathrm{~m} . \mathrm{snm}$, y es, además, una zona ecológica "quechua" (Pulgar Vidal 1940) en la cual predominan una serie de formaciones orográficas, prevaleciendo un paisaje de cerros y quebradas, utilizados con fines económicos y rituales de forma preponderante, desde fines del período

\footnotetext{
1 Departamento de Ciencias Históricas y Geográficas, Facultad de Educación y Humanidades, Universidad de Tarapacá. Av. 18 de Septiembre 2222, Casilla 6D, Arica, CHILE. Email: cochoquem@uta.cl; epizarro@uta.cl

2 El pueblo de Socoroma se encuentra ubicado en la comuna de Putre, provincia de Parinacota, en el norte de Chile. Para comprender los procesos de cambios y transformaciones en la población aymara, ver Choque (2009a y zoogb).
} 


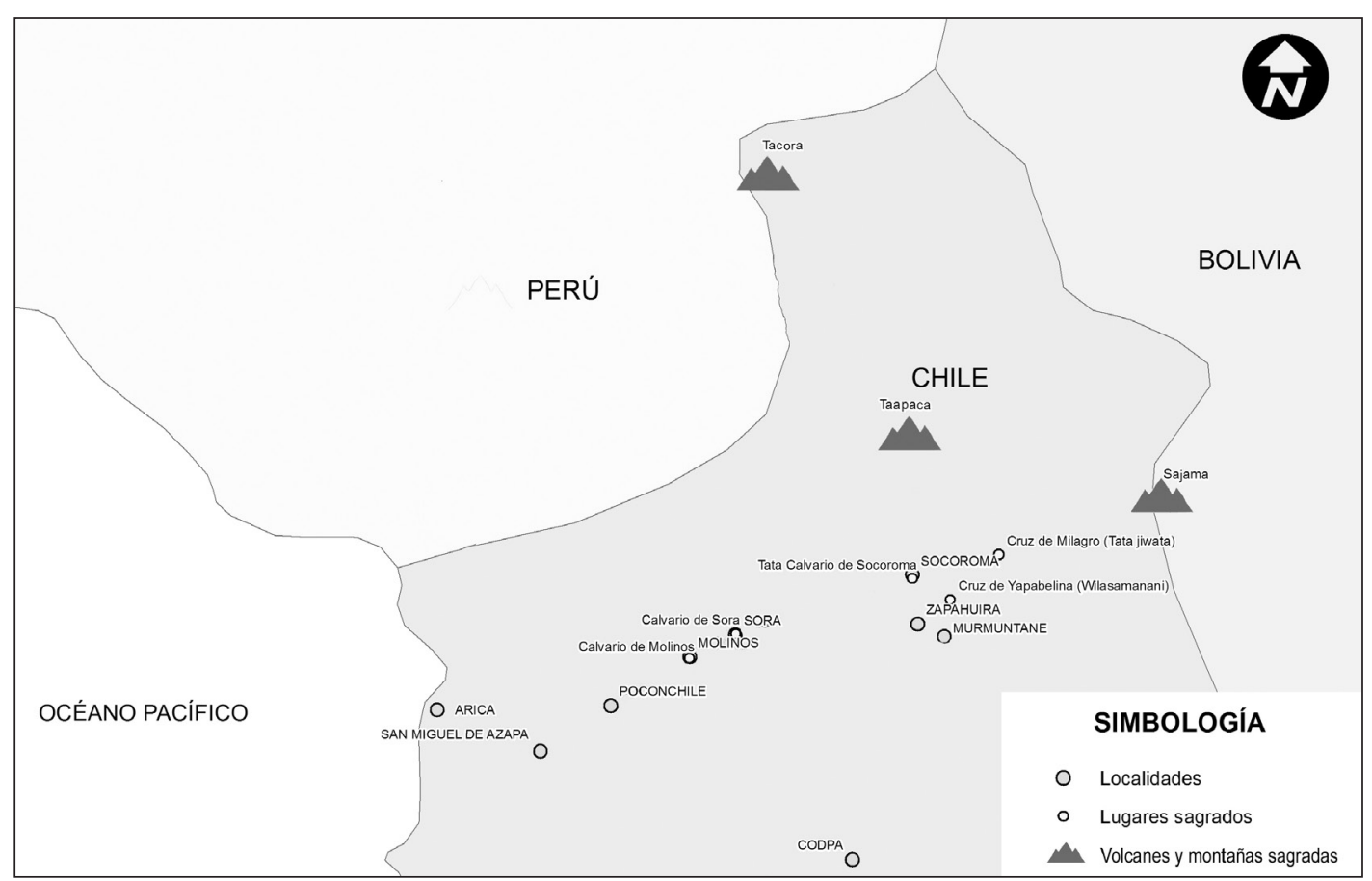

Figura 1. Mapa de ubicación de Socoroma, sus cruces principales y sus montañas sagradas.

Medio o Tiwanaku, es decir aproximadamente entre 700 y 1000 DC (Muñoz y Chacama 2006). En este marco, nuestras preguntas son las siguientes: ies posible identificar una relación entre los cerros de Socoroma y la identidad territorial? ¿Existen memorias sobre las actividades rituales que se realizan en los cerros? ¿Qué tipo de cultos o prácticas rituales existen sobre el agua y los cerros que puedan ser identificados actualmente en Socoroma?

Nuestra investigación permitió reconocer la complejidad ritual de la zona de estudio y comprender por qué los cerros son actores relevantes en la vida cotidiana y ritual de los habitantes de la comunidad, quienes viven de la agricultura. En este contexto, nuestra hipótesis considera que el culto a los cerros y el agua constituyen parte esencial de la vida social y cultural de los campesinos locales, expresándose en sus fiestas, calendarios rituales, tradición oral y las principales labores de la tierra, convirtiéndose además, en una expresión que le da sustento y validez a la identidad de los socoromeños. De acuerdo a lo anterior, nuestro objetivo es lograr comprender las expresiones rituales y la tradición oral sobre el culto al agua y los cerros en la comunidad andina de Socoroma, considerando su influencia en la creación de la identidad cultural de sus habitantes.

La existencia de continuidades y rupturas en las expresiones rituales son el resultado del cambio cultural, cuyas consecuencias se expresan en la reinterpretación de la identidad y del propio espacio sagrado de los habitantes de esta comunidad. Asimismo, se evidencia una readecuación del calendario ritual, motivado por el permanente despoblamiento y envejecimiento de su población.

\section{$*$ Cerros e identidad}

Los cerros sagrados constituyen desde épocas prehispánicas hasta la actualidad, la "base de las cosmologías y las mitologías. En torno a ellos se han generado creencias y se han desarrollado prácticas rituales, y a ellos se han ofrecido todo tipo de sacrificios" (Gil y Fernández 2008: 107). Esta concepción andina permitió generar una profunda relación entre el nacimiento y "las fuerzas ancestrales y sagradas de la naturaleza” (Albó 1992), creándose de este modo una interrelación de distintas fuerzas antinómicas 
que están en permanente interacción y fricción, donde la población humana debe articular e interactuar con seres "extrahumanos" y la propia naturaleza (Van den Berg 1989; Leoni 2005).

En este escenario, las investigaciones de Van Kessel en el área de estudio, han sostenido que los aymara han configurado una visión:

"[...] estructurada de su mundo, canonizada y sacralizada en su culto religioso y expresada ritualmente en el conjunto más antiguo de sus celebraciones religiosas, llamadas las costumbres dirigidas a los Mallku, la Pachamama y el Amaru" (Van Kessel 2003a: 199).

Estas visiones son elaboradas a partir del medio geográfico natural de una determinada región con sus diferentes pisos ecológicos, concibiendo una cosmovisión que:

"[...] ordena, organiza y efectúa su trabajo productivo, interpretando su actividad económica y dándole sentido y significado, mucho más allá de la simple subsistencia económica y la reproducción biológica" (Van Kessel 2003a: 269).

Eximiendo de cualquier sesgo dogmático al autor, consideramos que los mallku o cerros sagrados son los dispensadores de la vida, pues están íntimamente relacionados con la triada origen-abundancia-distribución del agua. No obstante, esta idea del mallku entre los aymara de la precordillera de Arica no existe como un concepto cercano y propio, sino que les resulta más apropiada la noción de achachila, que es "abuelo" o "antepasado" (Jorda 1981; Montes 1987; Albó 1992; Fernández 1995; Mamani 2002; Van Kessel 2003b).

Nuestra investigación en la comunidad andina de Socoroma permitió asociar e identificar los cerros sagrados con familias que han acudido a las celebraciones de las "cruces de mayo" o "celebraciones de cosechas" (Van den Berg 1989: 92)3. Si bien estas "fiestas de cosecha" tienen

3 Alaez ha sostenido conclusiones similares a las de Van den Berg, pues considera que existen vínculos permanentes entre los vivos, los espacios sagrados, los muertos y la protección de la comunidad: "[...] en la cosmovisión andina el mundo de los muertos no es algo separado del mundo de los vivos. Tanto es así que el hecho de morir no rompe los vínculos que había con la comunidad: el difunto sigue siendo comunero, aunque en una nueva situación. Hay una comprensión cultural de la el propósito de estimular las fuerzas reproductoras de la tierra, generando una comunión real entre los hombres y la deidad agrícola, también permiten la renovación de las relaciones recíprocas entre los dueños de la lluvia, los cerros y los humanos. Por tanto, la ejecución de libaciones y la preparación de la comida ritual -que Van den Berg identificó como waja y que en Socoroma se denomina guatia- son obligatorias para atender a los peregrinos que se dirigen a los cerros sagrados. Además, la fiesta cumple una función social y ritual, pues permite vincular a familiares y amigos con estos cerros. En tal sentido, la distribución de las familias en relación al culto a las "cruces de mayo" dispuestas en los cerros, se expresa de la siguiente manera: Mamani, Fernández, Huanca, Bolaños, Guarachi, Maldonado, Manlla, Vilca y Humire (Tata Calvario); Carrasco, Gómez, Sánchez, Vásquez, Huanca y Flores (Yapabelina); Cáceres, Calle, Paco, Vásquez, Mayorga, Choque, Gutiérrez, Cali y Alejandro (Milagro) 4 . Este vínculo entre linaje y cerro, posee una directa relación con la estructura del orden cósmico del espacio sagrado de los socoromeños y las representaciones míticas que poseen las diversas familias, hecho que permite la construcción de significados de identidad, contenidos míticos de legitimación social y política de los diversos linajes en el territorio. Tal como afirma Sanhueza (2008), este tipo de prácticas de identificación con el culto a las huacas y a los cerros, fueron un factor relevante en la organización del espacio y las prácticas sociales. Las huacas son por lo tanto, "el referente mítico que otorgaba a cada grupo social un profundo sentido de pertenencia identitaria y territorial" (Sanhueza 2008: 59).

La fiesta de la "cruz de mayo" en Socoroma, por lo general se extiende desde el 1 al 7 de mayo, convocando a los devotos de Arica y los valles costeros (Choque 2009a). Si bien existe heterogeneidad laboral entre los devotos y novenantes ${ }^{5}$, destacan entre ellos, los campesinos que

muerte, es bien asumida: así como nacemos, morimos" (2001: 174). Ver también Espinosa (1996), Mamani (2002), Lozada (2003).

4 Es posible identificar además, una asociación explícita entre cruces secundarias y familias devotas dentro de la clasificación general de cada cruz, tal como lo muestra Choque (2009a). Se suma a lo anterior que es la Santísima Cruz de la Virgen de los Milagros la que posee un número importante de devotos que mantienen un vínculo tardío con el pueblo, a diferencia de Calvario y Yapabelina que tienen una mayor antigüedad.

5 Es el gentilicio de la "novena", que se entiende como un ejercicio de devoción dedicada a Dios Padre, a Jesús, al Espíritu Santo, la 
provienen del valle de Lluta y del entorno de Socoroma, quienes suelen realizar las peregrinaciones más extensas y prolongadas a los cerros.

Los cerros de uso ritual se dividen en aquellos que están asociados a cultos menores o familiares y aquellos que están asociados a "espacios sagrados de ofrendas y peregrinaciones" (Moyano 2009: 42) ${ }^{6}$. No obstante estas clasificaciones, el cambio cultural vivido en Socoroma en el último siglo, y en particular a partir del proceso de "chilenización" de las comunidades andinas del norte de Chile, ha significado una alteración y transformación religiosa de importancia en la población local, pues se ha tendido a abandonar la veneración a los cerros de mayor prestigio y desarrollar un culto a cerros locales de la comunidad.

La base cosmológica de los socoromeños está íntimamente ligada a los cerros sagrados, cuya mayor expresión se produce en las celebraciones de las "cruces de mayo", manifestada a través de tres festividades y peregrinaciones simultáneas que se realizan al cerro Tata Calvario, a la Cruz de Yapabelina en el cerro Vila Samanani y a la Cruz de Milagro en el cerro Tata Jiwata ${ }^{7}$. Este uso ritual de los cerros genera espacios sagrados convergentes, que han tenido como centro de la tríada al cerro Tata Calvario, pues en él confluyen los achachilas y cruces que representan zonas ecológicas cercanas y distantes al territorio sagrado.

En vísperas del mes de mayo se incrementan los esfuerzos de fabriqueros, mayordomos y alféreces, cuya finalidad es asegurar la participación de fieles y devotos en la celebración de las "fiestas de cosecha". Este esfuerzo se realiza para festejar la fertilidad y maximizar la producción agrícola, y que coincide con los ritos choquelas del

\footnotetext{
Virgen María y a los santos. Si bien, se debe practicar por nueve días consecutivos con la intención de orar y reflexionar espiritualmente, en los Andes se ha reinterpretado a partir de la acción e influencia del tiempo festivo de la "octava". Asimismo, en muchos lugares se han reducido los nueve días a tres, denominándose tridúo en vez de novenario, aunque conservando el nombre de "novenante".

6 Sobre lo mismo, Mignone (2010) considera que algunos cerros o montañas son centro de peregrinaje a causa de apariciones milagrosas o manifestaciones sagradas.

7 La traducción para los nombres de los cerros es la siguiente: Tata Calvario (Abuelo Calvario), Vila Samanani (aliento como de sangre) y Tata Jiwata (abuelo fallecido).
}

altiplano occidental de Bolivia, ligados a la producción de papa. Las "fiestas de cosecha" de Socoroma y del altiplano poseen elementos afines, ya que se realizan en torno a las fiestas de la "cruz de mayo", pero están distanciadas en su expresión ritual por efecto de los cambios culturales, no gozando los socoromeños de la danza y música de los aymara del altiplano (Sigl 2009). Respecto a los significados y aspectos simbólicos de estas fiestas, los ritos se dirigen a los mismos destinatarios, los cerros, que son el origen de las fuerzas meteorológicas y antiguas divinidades de la lluvia (Bouysse-Cassagne y Harris 1987).

Este despliegue ritual se inicia con las "súplicas" de participación, que dirigen los alféreces a los mayordomos que cada cruz tiene asignada, de acuerdo al siguiente orden: Santísimo Calvario, San Francisco y Crucificado; Cruz de Yapabelina, Virgen del Rosario y Virgen del Carmen; y Cruz de Milagro, Virgen de Candelaria y Santa Lucía. Estos esfuerzos buscan, además, la aprobación de los santos patronos (San Francisco y Virgen del Rosario) y de los santos principales para realizar las peregrinaciones a los cerros que poseen adoratorios de primera importancia (Mignone 2010). Esta devoción a los cerros sagrados y a los espíritus que en ellos habitan se sustenta en el hecho de que éstos cumplen el rol de vigilar y proteger a los socoromeños, y por ello, los habitantes del pueblo deben "tenerlos propicios por medio de pagos” (Marzal 1992: 42).

La festividad de las cruces tiene como destinatarios finales a los cerros sagrados de Socoroma, siendo un culto de carácter local, pues no se realiza una peregrinación regional, ya que estos cerros son de carácter secundario, y han reemplazado a los achachilas principales en los ritos oficiales y tradicionales. Además, los cerros Calvario, Yapabelina y Milagro están acompañados de cerros menores y samiris que son "la residencia de las cruces secundarias" como lo señaló Van den Berg (1989) para el altiplano boliviano. Contrariamente a su rol actual, en el pasado estos cerros ejercieron el papel de intermediarios con los achachilas principales como Taapaca, Tacora, Sajama e Illimani, entre otros ${ }^{8}$. Entonces, los cerros locales son los que reciben dones y ofrendas para solicitar su mediación con los cerros principales, manteniendo así el

\footnotetext{
8 Bouysse-Cassagne y Harris (1987) sostienen que los cerros son los guardianes de la comunidad, y por más pequeños que sean, participan del poder otorgado por las cumbres altas.
} 


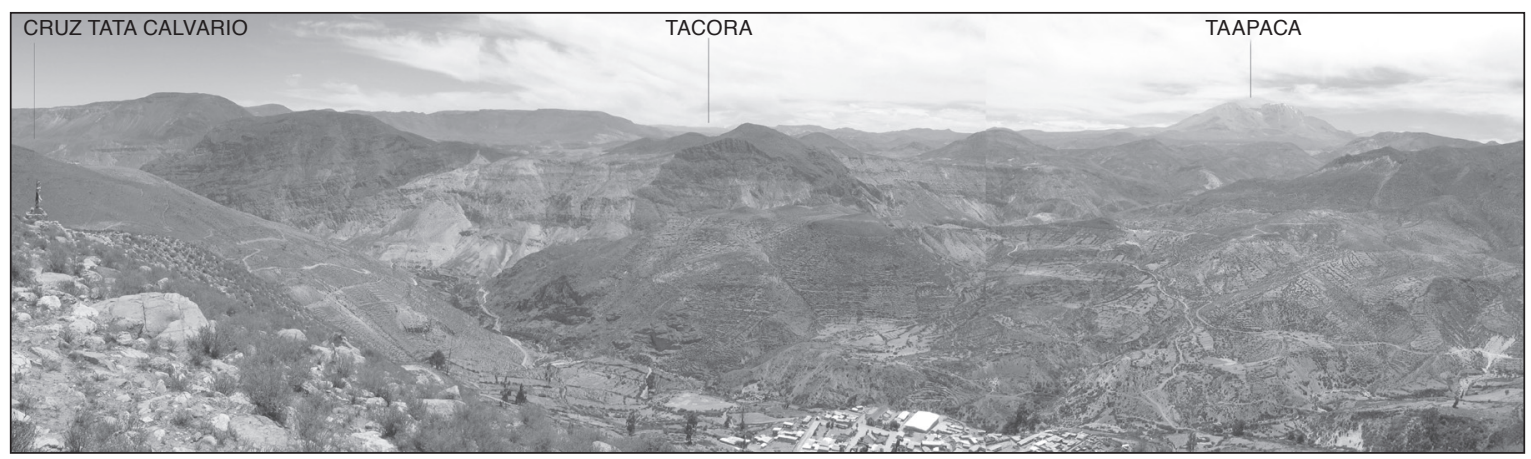

Figura 2. Tata Calvario, Tacora y Taapaca. Fotografía: Carlos Choque, 2009.

equilibrio con las fuerzas antinómicas. Asimismo, constituyen un espacio donde los campesinos agradecen por las cosechas de la temporada y hacen súplicas para tener agua en los meses subsiguientes, pues son los achachilas "los que dominan la lluvia y la sueltan y así fecundan la tierra; o la retienen causando la infecundidad" (Van den Berg 1989: 177).

En el caso de Socoroma, el vínculo ritual entre los cerros secundarios y principales es evidente, pues la orientación espacial de las apachetas y adoratorios del Tata Calvario, el Yapabelina y el Milagro, están relacionados visual y ceremonialmente con el Taapaca y el Tacora (Figura 2) ${ }^{9}$. También se observa un nexo entre los cerros secundarios y las familias devotas de cada cruz. Esta relación se expresa en los siguientes testimonios:

"Mi mamá es devota del Calvario, cuando no haya nadie que se haga cargo, yo voy a responder por mi familia y realizaré las costumbres" (Jova Bernabé Vilca 2010).

"Nosotros siempre hemos sido milagreros y hace más de 40 años que vamos a acompañar a la Cruz de Milagro" (Neri Choque Mamani 2010).

"Mi Familia siempre ha sido devota de Yapabelina" (Regulo Huanca Vásquez 2010).

Esta vinculación ritual con los achachilas permitió generar una identidad asociada a los cerros sagrados, a los símbolos que existen en ellos y a los espacios adyacentes, lo cual

9 Ver Reinhard (2002). permite la apropiación de los achachilas por parte de los sujetos, pues éstos son los antepasados de la comunidad desde tiempos míticos (Gisbert 1980; Bouysse-Cassagne y Harris 1987; Van den Berg 1989).

Igualmente, la idea de la "costumbre" para los socoromeños implica ejecutar y dedicar de forma obligatoria los ritos y liturgias a los cerros sagrados, lo que debe ser realizado según las normas culturales y rituales existentes, de lo contrario se efectúan una serie de amonestaciones públicas que apelan a la relación de ritualidad e identidad local.

El concepto de identidad es una idea impuesta masivamente en las ciencias sociales a partir de la década de 1980 y más todavía en la década siguiente. Al respecto, Albó, indica que la "identidad" comienza con el reconocimiento y aceptación de la propia personalidad (el "yo"), pero tiene en seguida su "expansión social natural al sentirse parte del grupo social básico de referencia, de un nosotros" (1999: 90). Señala, también, que los procesos demográficos y migratorios expanden, reducen o trasladan a los pueblos sin que por ello pierdan automáticamente su identidad. En este caso, son los componentes simbólicos los que permiten el aglutinamiento e inclusión de las antiguas formas de ser y las memorias de los territorios de origen. Además, la construcción de la identidad es muy compleja, porque cada individuo está siempre en una encrucijada entre sus varias identidades grupales: como hombre o mujer, como niño, joven o viejo, por su lugar o territorio más amplio de nacimiento y residencia, su profesión, su religión, sus opciones y opiniones, entre otros. Enfatizando una u otra identidad, de 
acuerdo a quiénes se quiere parecer o de quiénes se quiere distanciar en determinadas situaciones concretas. Hay siempre una serie de estrategias más estables o cambiantes, más individuales o colectivas en el manejo de identidades. Por lo tanto, la construcción de la identidad tiene la capacidad de considerarse a uno mismo como objeto e ir construyendo narrativas familiares y de sí mismo mediante las relaciones sociales, actos simbólicos y reciprocidades en un contexto ritualizado. ${ }^{10}$

El resultado de esta relación entre cerros sagrados e identidad ha generado una regulación social de los actores convocados a las actividades rituales, ya que delimita la posición del linaje en la fiesta. Es decir, las identidades dependen de los contextos específicos en que los actores se ven implicados, junto a sus percepciones sobre dichas situaciones (Barth 1976; Ember et al. 2006), pues la identidad puede construirse y manipularse desde dentro o desde afuera de los espacios culturales y sociales ${ }^{11}$. Esta perspectiva coincide con los postulados de Hall (1990), ya que la identidad es construida de múltiples maneras a través de los discursos, prácticas y posiciones diferentes, no siendo unificada, sino más bien fragmentada y fracturada. Así, la identidad se construye desde las representaciones de la historia, la lengua y la cultura que genera cada sociedad. ${ }^{12}$

Un indicador de esta relación entre achachila e identidad es posible de observar el día 2 de mayo, ya que luego

\footnotetext{
${ }^{10}$ Moyano considera que las "prácticas rituales vinculadas con la adoración a las montañas se explicarían como la instrumentalización de las distintas estrategias de dominación y resistencia, entre los incas y los grupos locales" (2009: 42), lo cual implica necesariamente un proceso de identificación étnica a partir de los símbolos y espacios sagrados de determinadas sociedades indígenas.

${ }^{11}$ Barth (1976) señala que las culturas están cambiando continuamente por innovación, por extraversión, por transferencia de significados, por fabricación de autenticidad o por modernización, pero esto no significa automáticamente que sus portadores también cambien de identidad.

${ }^{12}$ Hall consideró, además, que la identidad en su significado tradicional es una "mismidad omniabarcativa, inconsútil y sin diferenciación interna" (1990: 18). Posturas teóricas similares son posibles de encontrar en Laclau (1993), quien cree que la identidad surge a partir del poder, y en Brah, quien establece que la construcción de la "identidad está determinada por experiencias construidas culturalmente, en relaciones sociales, creando identidades colectivas" (1996: 126).
}

de recibir ofrendas y challas ${ }^{13}$, las cruces son "vestidas" según un orden preestablecido por los linajes, sin que exista oportunidad de subvertir las normas existentes según dicta la "costumbre" y posición de cada familia en la estructura social de la comunidad. Otro indicador del despliegue de las identidades es aquel que se produce en la procesión de las cruces principales y secundarias, que convergen en el sector denominado "crucero" desde tres puntos cardinales definidos y opuestos, los cuales son una proyección de su entorno espacial y área de influencia (Figura 3).

En esta convergencia e intersección en el "crucero", se realizan saludos recíprocos entre las diversas cruces, pues las reverencias se expresan dependiendo de su jerarquía, para luego presentar sus respetos a las imágenes de los santos de la iglesia de Socoroma. Cabe destacar el rol e importancia del Tata Calvario, que se erige como el más antiguo y sagrado y que ejerce un rol adicional, pues es el taypi o el centro de la territorialidad sagrada de Socoroma; las cruces de Yapabelina y Milagro son una representación de las áreas periféricas y marginales del territorio. De igual manera, la convergencia de las procesiones y su ingreso a la iglesia se produce en estricto orden jerárquico.

Considerando lo expuesto, se evidencia una asociación de mitos de origen y de ocupación del espacio, ya que los linajes asociados al Tata Calvario se erigen como los más importantes y antiguos, a diferencia de los devotos de la Cruz de Milagro, que han deconstruido su identidad socoromeña a partir de su presencia en los límites occidentales del territorio ${ }^{14}$. Además, estas deidades no

${ }^{13}$ Challa: nombre genérico del rito de libación de líquido (Mamani 2002).

${ }^{14}$ El concepto de "deconstrucción" elaborado por Derrida, intentaba traducir y reapropiar para sus propios fines los términos heideggerianos Destruktion y Abbau, que abordaban los problemas de la estructura y la arquitectura de la metafísica occidental. Desde una perspectiva filosófica, la deconstrucción exige la fragmentación de textos, y en ella, el filósofo detecta los fenómenos marginales, anteriormente reprimidos por un discurso hegemónico. Es por ello que la deconstrucción no busca "sentidos", sino huellas de ideas; $y$ con ello retoma conceptos básicos de la psicología freudiana, que investigó las diferencias y contradicciones del alma humana. En consecuencia, usaremos el concepto de deconstrucción, considerando que las comunidades andinas van redefiniendo sus identidades y narrativas a partir de factores sociales, culturales y políticos, repitiendo así la lógica de Derrida, pues "retoman y modifican 


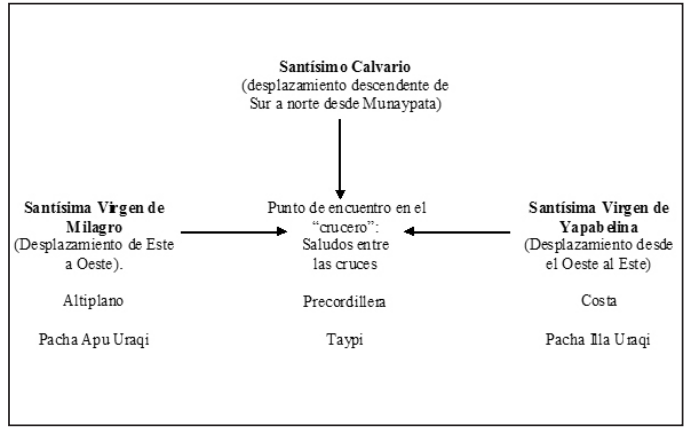

Figura 3. Encuentro de las Cruces ("crucero").

solo reciben ofrendas rituales o libaciones, sino también ofrendas musicales que poseen un fervor evocativo y simbólico, como queda expresado en el siguiente párrafo:

\section{"Nuestra Señora Milagro, yo nunca te olvidaría (bis) \\ Qué contentas te has quedado y yo me vine llorando \\ Si nos conservas la vida para el año volveremos \\ El día que yo te olvide será cuando yo me muera \\ Tu nombre pronunciaría hasta mi última agonía \\ Esto te digo cantando, tú te acordarás llorando (bis) \\ Culis, culis, culis".}

En suma, la creación de jerarquías de linajes y cerros va en concordancia con la ubicación e importancia de los santos patronos y santos secundarios, pues delimita un orden y una estructura espacial a los cuales deben apegarse los alféreces y mayordomos de la iglesia ${ }^{15}$. Esta estructura nace de la función sacralizada y genésica de los cerros, hecho que permite la configuración de una cartografía sagrada local que tiene como centros distintivos los adoratorios y santuarios de Milagro, Yapabelina y Calvario. Igualmente, la existencia de tales santuarios de peregrinación representa una perpetuación de las estrategias de conquista y ocupación ritual de los socoromeños sobre la periferia de su territorio. Así, el rol simbólico de las montañas sagradas y los santos patronos perpetúa en el

libremente los fragmentos filosóficos" (Krieger 2004: 187).

${ }^{15}$ Como hay santos para cada profesión, enfermedad y situación de vida, también las deidades andinas practican la "división de trabajo" en la protección y el cuidado de los seres vivos: "El Apu más cercano cuida el ganado, el pukyu (manantial) la salud, la Pachamama protege a los seres humanos de los espíritus malignos (soq'a), y el illapa (rayo) tiene el control sobre las tempestades" (Espinoza 1987: 454). tiempo las ideas de la jerarquización de este tipo de cerros desde tiempos lejanos, hecho que ha sido también observado en otras regiones de los Andes (Poole 1982; Marzal 1992; Gutmann 1993; Wissler 2010).

\section{* Memorias de labores: "pasteando el cerro"}

Los Andes está dominado por cerros y nevados, "imponentes protagonistas del paisaje que han influido fuertemente en los modos de pensar de los andinos" (Gil y Fernández 2008: 106). Los cerros emergen en el paisaje con significados y dones que deben ser tomados en cuenta, pues en "caso contrario pueden desatar su ira sobre la población y en oposición pueden bendecir y proteger a quienes cumplen con la entrega recíproca de dones" (Bouysse-Cassagne y Harris 1987: 44). Socoroma no es distinto de otras comunidades andinas, pues ha generado una permanente interacción con los cerros en las prácticas rituales y en la vida cotidiana.

En el s. XIX, Socoroma tuvo un papel importante en el comercio con Bolivia, además de poseer numeroso ganado ovino y equino, que conservó hasta la construcción de la carretera internacional con Bolivia en el año 1960 (Choque 2009b). El rápido acceso a la costa y a Bolivia en camiones, provocó la extinción de caballares, asnos y acémilas, reduciéndose hoy a una mínima expresión. No ocurrió lo mismo con el ganado ovino, que perduró en importante cantidad hasta mediados de la década de 1980. En tal circunstancia, Socoroma ostentó una tradición pastoril ovina que fue mantenida por niños y adolescentes, quienes pasaban largos períodos con los rebaños en cerros y quebradas, y como dice Albó, en el altiplano "una de las primeras tareas productivas será probablemente acompañar a quienes llevan los rebaños a pastorear" (1992: 93). Si bien este autor se refiere a los camélidos, el caso del ganado ovino en la sierra tiene idénticas expresiones, ya que es la familia, y en especial los niños, los encargados de su cuidado en los pastos naturales que están ubicados en terrenos no aptos para la agricultura, tal cual indican Serracino y Stehberg (1975), para el caso de la vida pastoril en las quebradas altas de Atacama.

Durante esta investigación, nos dimos cuenta que los entrevistados evocaron recuerdos sobre las actividades 
pastoriles que desarrollaron en la niñez, siendo este trabajo una de las primeras actividades que desarrollaron en "ayuda a sus padres". Por lo tanto, cuando "despertaron", estuvieron "pasteando" en los cerros de la comunidad. Esta práctica les permitió aprender las nociones de trabajo colectivo y forjar la base de la personalidad andina así como la transmisión de los principios de reciprocidad y colaboración que son esenciales tanto en la vida diaria como en los ritos agrícolas (Arteaga y Domic 2007). En este contexto, los niños socoromeños "despertaron pasteando" los cerros Tarucachi, Vilque, Calvario, Markuma y Chatiza, siendo en ellos donde se reprodujeron y reelaboraron memorias, como también fueron espacios de interacción social, similares a las libaciones evocativas y challas de memoria que son efectuadas en vísperas de fiestas rituales.

Los cerros son espacios frecuentes para la realización de juegos de memoria en los anatañ cancha (campo de juegos), pues en ellos se efectuaron actividades dirigidas a recordar, reproduciendo así los caminos de memoria que sugiere Abercrombie (2006). Los siguientes testimonios muestran esta situación:

"Varias de nosotras salíamos con los corderos en la mañana. El fiambre que nosotros teníamos era tostado con charqui. Nosotros pasábamos pasteando mientras que los adultos estaban en fiestas. Allá nos juntábamos todos en el cerro y hacíamos fiestas, bailábamos también. Sabemos esperarnos los niños. Había animales, hartos, ovejas y vacas. Había pasto, iel cerro verde! ilas ovejas hartos!, las ovejas solo se pasteaban, ahora no hay nada" (Francisca Huanca Carrasco 2010).

Si bien nuestro propósito central es acceder a las memorias de las labores que se realizaron en los cerros, es posible identificar no solo los espacios de construcción de memorias y los comportamientos de los jóvenes pastores que ejecutaron representaciones rituales y reafirmaciones de su identidad en un entorno que no es el hogar o el pueblo mismo, sino que éstos se produjeron en sectores específicos de los cerros que tuvieron espacios y artefactos mnemotécnicos para la reelaboración de la memoria. Lo anterior coincide con los planteamientos de Abercrombie (2006), pues el paisaje, y en nuestro caso el cerro, ha constituido un estimulante permanente para la reproducción de memorias en la población indígena.
Estos sectores de los cerros son los refugios para la lluvia, los abrevaderos y sitios de juegos construidos por los niños. Además, estos lugares no tuvieron la categoría de "espacio salvaje", donde las fuerzas incontroladas de la naturaleza y el Manqha Pacha expresan su poder hegemónico. En vista de ello, algunos sectores de los cerros de Socoroma poseen una connotación dual y ambigua, ya que generan temores e inseguridades en los adultos, pero para los niños pastores son un espacio de seguridad y de interacción sociocultural, como es el caso del Tata Calvario, Tarucachi y Vilque, pudiendo éstos representar una extensión del espacio sagrado, ya que su entorno está "protegido" por las cruces del pueblo. ${ }^{16}$

La reproducción e interacción sociocultural no se expresan en un área indefinida ni se identifican al azar, sino que se asocian a huellas mnémicas y a narrativas que tienden a difundir la existencia de espacios culturales que son reutilizados por cada generación de pastores, como es el caso de la cancha del Tata Calvario ${ }^{17}$. Es necesario precisar, además, que en la cima del Tata Calvario se encuentran dos canchas, la más oriental construida en teoría por los niños que nacieron entre 1945 y 1955; no obstante, esta apropiación inicial es rechazada por los entrevistados que nacieron entre los años 1916 y 1929, pues expresaron que este espacio de juegos ya estaba ahí en la década de 1930. En suma, este espacio es un estímulo para abrir los "almacenes" mnémicos en cada generación de pastores, los que fueron reutilizando las mismas áreas de juegos y produciendo nuevas memorias o reelaborando las mismas. ${ }^{18}$

El antañ cancha en el cerro Tata Calvario, es un espacio donde el juego está acompañado de la reproducción de ritos y costumbres, donde los niños pastores ejercieron

\footnotetext{
${ }^{16}$ Martínez (1983: 86-87) expresó un argumento similar, al hacer notar la "ambigüedad" que rodea a las ideas y prácticas en torno a los cerros al interior de la provincia de Iquique, en la región de Tarapacá.

${ }^{17}$ Cancha: espacio despejado, cercado o no, que se utiliza para realizar diversos tipos de actividades, ya sea rituales, económicas, u otras. Corral de animales. Campo deportivo.

${ }^{18}$ Dada la cantidad de líquenes, arbustos existentes y la acumulación inusual de piedra laja en la primera cancha, es posible estimar que es anterior al s. XIX, en tanto la segunda posee una elaboración más reciente, es decir de inicios del s. XX, pues está desprovista de cualquier infraestructura.
} 
roles de fabriqueros, mayordomos, küjraria ${ }^{19} \mathrm{y}$ "servicios", generando un thakhi de memoria que los llevó a dramatizar procesiones con representaciones simbólicas de los santos y vírgenes, como también fiestas de siembra de papa o pachallampe (festejo a la tierra con cariño) y la anata (carnaval). Es también el anatañ cancha el que permitió la generación y reelaboración de significados en torno a determinados ritos, así como la creación de huellas mnémicas que se expresaron en el futuro inmediato y lejano. La recurrencia de recuerdos sobre el tiempo de pastoreo, también estuvo asociada a la existencia de una infancia que exigió sacrificios y privaciones, siendo el pastoreo un tiempo de juegos y de responsabilidades limitadas, tal como lo expresara Poma de Ayala (1992 [1613]).

En cambio, durante la adolescencia las actividades relacionadas con la tierra y las difíciles condiciones de vida obligaron a los jóvenes a desvincularse de sus grupos familiares para ganarse la vida en la ciudad o valles costeros como Azapa y Lluta, culminando así el tiempo de juegos y alegrías. El factor que contribuyó a la ruptura de la reproducción ritual fue la instalación de la educación estatal y la introducción de las agencias gubernamentales en Socoroma desde mediados del s. XIX, ya sea de parte del gobierno peruano, o más tarde, del chileno. Durante la segunda mitad del s. XIX -en el período de estabilidad institucional de Perú- hubo intentos de modernizar la región mediante la construcción de obras públicas y una reorganización de la administración civil del territorio. Con anterioridad a la Guerra del Pacífico existieron varias escuelas en la ciudad de Arica y seis en las zonas rurales de Codpa, Socoroma, Putre, Livilcar, Lluta y Azapa (Palacios 1974: 78). Considerando la información aportada por este autor, entre los años 1866 y 1879 se habrían creado las escuelas de Socoroma, Livilcar y Molinos, ya que antes de 1866 los hijos de los socoromeños más pudientes debieron asistir a la escuela parroquial de Putre o Belén.

\footnotetext{
${ }^{19}$ Küjraria: palabra de raíz aymara que se refiere a la persona encargada de prender las velas de los altares para Semana Santa y en los diversos días de la semana, pues cada santo posee un día en específico. Los kujrarios realizaban la vigilia para Semana Santa en la sala, y los mayordomos les llevaban las comidas, refrescos y cueros para dormir. Asimismo, ejercieron el rol de acompañar a los mayordomos en las diversas labores rituales o reemplazarlos cuando no estaban en el pueblo, ya sea por motivos laborales o de viaje. En general, eran personas solas o mayores.
}

Concluida la Guerra del Pacífico, el territorio quedó bajo la tutela del Estado chileno, iniciándose el proceso de "chilenización", definido por Aguirre y Mondaca (2011) como un "disciplinamiento social" de la población local, basado en la articulación sociopolítica de los comuneros indígenas, quienes fueron ciudadanos activos en las disputas nacionales, ya que desarrollaron "estrategias políticas, económicas, sociales y culturales" (2011: 7). Para estos autores, la "chilenización" aplicó políticas administrativas para implantar la burocracia estatal, implementando una educación que fomentó la "chilenidad", trasladando población desde otras partes del país y expulsando o facilitando la partida voluntaria de ciudadanos peruanos. Las consecuencias de estas políticas liberales y modernizadoras peruanas y chilenas, fueron el alejamiento de los ritos y costumbres por parte de la población indígena, que en la segunda mitad del s. XX se vio obligada a deconstruir y reinterpretar su propio espacio sagrado, así como su calendario ritual.

Por consiguiente, el pastoreo de ovejas en los cerros fue un tiempo de aprendizaje, de reafirmación de la identidad entre los jóvenes pastores y un espacio para las prácticas de los ritos comunales e interacción con el espacio sagrado. Debemos agregar además que la antañ cancha y los cerros, permitieron la deconstrucción de nuevas memorias, teniendo como contexto la territorialidad sagrada de su entorno ${ }^{20}$, ya que los cerros son considerados como testigos del tiempo y puntos privilegiados del paisaje mítico (Rivière 1979; Gil y Fernández 2008). Asimismo, toda práctica cultural en los linderos del Tata Calvario, Qachuchatiza o cerro Socoroma, consolidó el sentido de identidad de los socoromeños y constituyó un espacio privilegiado de su devenir histórico y cultural. ${ }^{21}$

\footnotetext{
${ }^{20}$ La cancha está dominada visualmente por los volcanes Tacora y Taapaca, como también por las cruces de Cruz Vilque y Calvario, además de los cerros Orqo Chatiza, Qachu Chatiza, Socoroma y Tarucachi.

${ }^{21}$ Otro espacio de permanente interacción social entre los niños y adolescentes que se dedican al pastoreo es la cancha de Viscachune, ubicada entre los cerros Qachuchatiza y Kalacruza. Esta cancha es de mayores dimensiones y fue utilizada hasta mediados de la década de 1970 por la población adulta para sus reuniones deportivas con los pueblos vecinos, pero su funcionalidad es similar, pues en este espacio hombres y mujeres construyen sus propias memorias.
} 
* Ofrendas a los cerros y al agua EN SOCOROMA

En el transcurso del s. XX, los socoromeños, por efecto del "blanqueamiento cultural" (González 1997), las políticas de "chilenización" (Palacios 1974; Aguirre y Mondaca 2011), y migración permanente a las ciudades, han sufrido el debilitamiento de sus costumbres (Van Kessel 2003b). Éstas fueron perdiendo la especificidad de algunas prácticas rituales, obligando a las generaciones más jóvenes a realizar permanentes esfuerzos para rememorarlas en determinados contextos rituales, que Abercrombie (2006) denominó amtañ thakhi o "caminos de memoria", y que son desarrollados por los mayordomos y fabriqueros. Los despliegues narrativos originados en el amtañ thakhi requieren de permanentes libaciones de bebidas alcohólicas, ya que ejercen la función de artefactos mnemónicos que permiten el desarrollo de variadas técnicas de memoria, rompiendo así las fronteras de la dimensión temporal del espacio y la vida humana (Sharon 2004).22

Los "caminos de memoria" han permitido a los socoromeños traer al presente el pasado lejano de los linajes de la comunidad, así como articular los ritos practicados en el espacio sagrado. No obstante, dicha práctica se ejecuta en estricto orden jerárquico y de acuerdo al prestigio social y ritual de las cruces y mayordomías, realizándose una secuencia de mayor a menor que permite la producción de una reciprocidad sagrada entre las diversas divinidades convocadas a la challa (Figura 4). En suma, estos "caminos de memoria" son realizados durante las ceremonias de las "cruces de mayo", las fiestas patronales y los ritos de emergencia.

A continuación, hemos dividido la discusión en dos partes, la primera de ellas busca evidenciar el rol de los difuntos en el culto a los cerros y al agua, en tanto la segunda se refiere a los tipos de ofrendas que se entregan a los cerros y al agua en Socoroma. ${ }^{23}$

\footnotetext{
${ }^{22}$ Este autor considera que ciertos individuos en determinados contextos rituales y con ayuda de artefactos mnemotécnicos, pueden recordar hechos anteriores a la propia vida y remontarse a un tiempo lejano y mitológico.

${ }^{23}$ Debe considerarse que los cerros están estrechamente vinculados con las fuerzas metereológicas y con el rayo, por tanto, a las lluvias y nevazones (Bouysse-Cassagne y Harris 1987).
}

En primer lugar, se debe mencionar que los andinos siempre han generado cultos a los cerros y volcanes, porque los interpretan como espacios de creación y sitios fundacionales de sus linajes (Rostworowski 2000). Además, Bouysse-Cassagne y Harris (1987: 37) señalan que los antiguos sepulcros de los muertos aún "dominan el espacio y juegan un papel en los quehaceres de los vivos". Esta relación entre vivos y muertos no solo se ha expresado en la existencia de chullpas o aldeas prehispánicas en los cerros que existen en el entorno de Socoroma, sino también en tumbas contemporáneas donde fueron depositados aquellos niños que murieron antes de nacer o apenas nacidos. Estas tumbas están ubicadas en las laderas del noreste del cerro Kalacruza, donde existe además una aldea prehispánica del período Intermedio Tardío (1000-1450 DC; Muñoz y Chacama 2006). También existen otras tumbas informales localizadas en el sector de Tara, en la entrada oriental del pueblo. Asimismo, enterrar a los nonatos o muru wawas es parte de una ideología extendida en los Andes, pues existe una fuerte relación entre el nacimiento y "las fuerzas ancestrales y sagradas de la naturaleza" (Albó 1992: 90). Lo anterior implica que los niños pertenecen al mundo ancestral, y al morir en la gestación o de manera temprana, deben ser entregados ritualmente a los achachilas para así restituir el equilibrio de las fuerzas sagradas. No obstante, las narrativas contemporáneas solo se limitan a expresar que estos entierros informales fueron costumbre de "gente antigua" y de mujeres "maldadosas" que abortaban, pero los significados poseen una vinculación más profunda con las ideologías de la muerte y los espacios sagrados. ${ }^{24}$

En Socoroma la asociación directa de los difuntos con el mundo de los vivos se expresa a partir de los ritos de siembra de papa (pachallampe) que se realizan en los pueblos de Putre, Socoroma y Pachama durante la primera semana de noviembre. El pachallampe es un rito que coincide con la celebración de los Santos Difuntos, donde a los muertos se les solicita lluvia para hacer fructificar los sembrados. Desde una perspectiva ritual, esta fiesta posee un profundo contenido simbólico y emocional, ya que

\footnotetext{
${ }^{24}$ Rostworowski (2000) ofrece un argumento que valida las concepciones andinas sobre los difuntos y su rol influyente en la vida humana, pues los mallku estarían siempre vigilando a los humanos.
} 


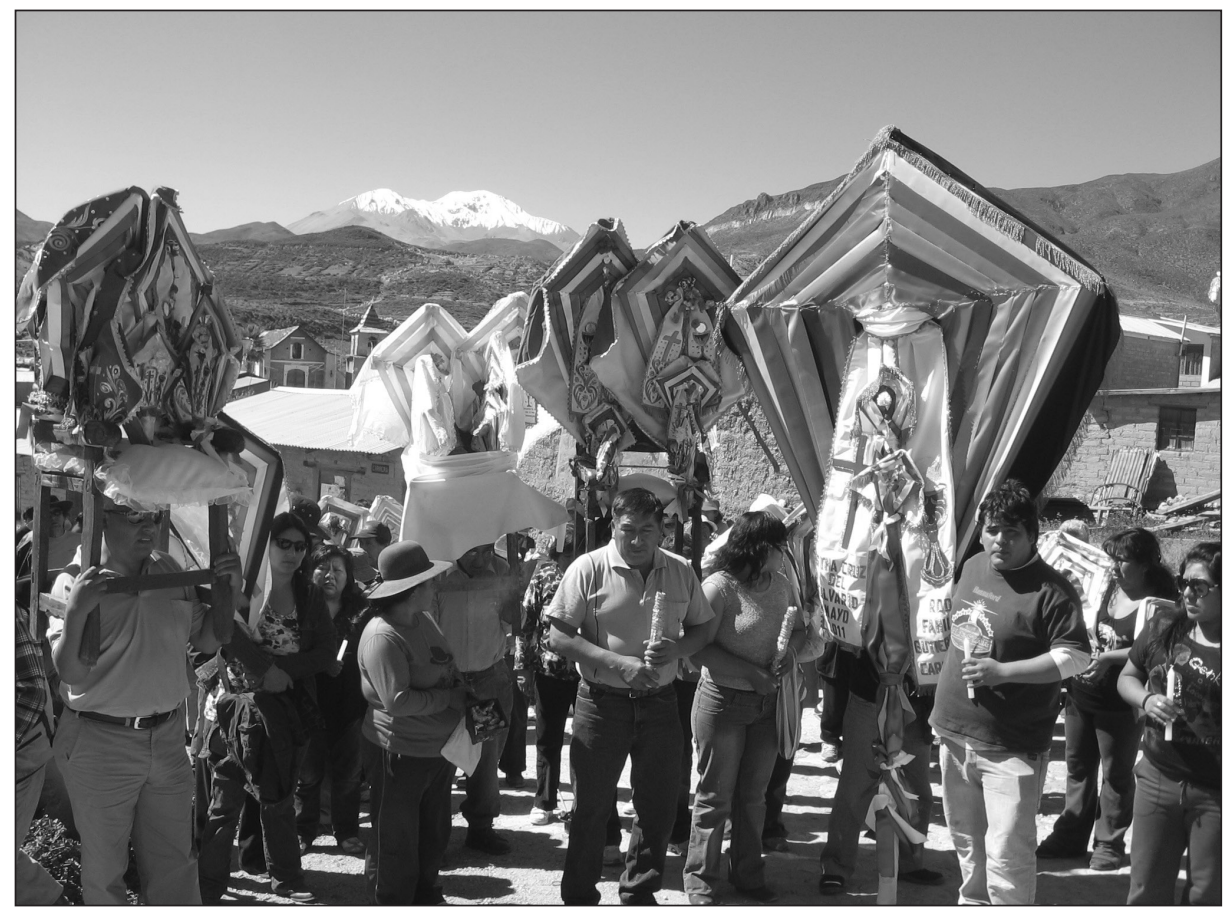

Figura 4. Procesión de las cruces del Tata Calvario, Yapabelina y Milagro, en Socoroma. Al fondo se observa el volcán Taapaca. Fotografía: Carlos Choque 2011.

pone en vigencia los vínculos sociales y del sistema de reciprocidad entre los comuneros y las deidades andinas (Mamani 2002).

Debemos agregar que el rol de los difuntos en los ritos de lluvia son duales, ya que por una parte, "las almas nuevas" son intermediarias y portadoras de las súplicas de los seres vivos por agua; $y$ por otra, las "almas antiguas" o tukut alma apxata actúan como receptoras de los ritos (Van den Berg 1989), ya que poseen vínculos estrechos con los achachilas o antepasados mitológicos y "tienen el poder de proveer de las lluvias o de impedirlas cuando no se las ha tratado en la forma debida" (Bouysse-Cassagne y Harris 1987: 37). En el caso de Socoroma, las súplicas por el agua a los difuntos se han expresado de manera oficial por parte de los mayordomos durante la challa, en el altar del "alma mundo" del cementerio, momento en el cual se recuerdan los distintos difuntos de la familia y de la comunidad, a los cuales se les solicita interceder ante Dios para que envíe las lluvias. Estas mismas plegarias son expresadas simultáneamente ante el Tata Calvario, el cerro principal.
En segundo lugar, la expresión del culto religioso de Socoroma está íntimamente asociado a los ciclos agrícolas, tal como ocurre en otras expresiones de religiosidad aymara (Van den Berg 1989; Fernández 1995; Rösing 1998; Van Kessel 2003a), y por lo tanto, todo el despliegue ritual y simbólico que es realizado por los mayordomos y fabriqueros de Socoroma, está estrechamente ligado al ciclo de siembra, crecimiento y cosecha del cultivo del maíz y la papa. Como ya señalamos, la fiesta de las "cruces de mayo" son un culto destinado a los achachilas, la cual también incluye al agua, ya que este culto está relacionado con el "arco", pero a éste no lo encontramos en la inauguración, sino en la clausura del ciclo agrícola, y precisamente en la celebración del día de las "cruces de mayo" (Van Kessel 2003b). Si bien la presentación del "arco" en la fiesta de dichas cruces está en desuso en Socoroma, no ocurre lo mismo en sus antiguas extensiones territoriales de la costa, ya que su uso es predominante entre los sectores de Tambo de Huanta y Milluni, en el valle de Lluta. No obstante, el "arco" sí aparece en la fiesta de San Isidro, el 15 de mayo, cerrando así el período de las fiestas de cosechas en el pueblo. 
Las ceremonias destinadas a los cerros y al agua son realizadas en distintos momentos del calendario ritual, coincidiendo con los ciclos agroclimáticos de roturación, siembra, pre-cosecha y cosecha. Por lo tanto, los comensales "extrahumanos" son muy diversos, por lo cual no se puede dejar de invitar a los achachilas, a la Pachamama, a la Mamacota, a los gentiles y a los santos principales. Asimismo, la totalidad de los ritos realizados en Socoroma son presididos por los fabriqueros, mayordomos y alféreces, contando además con la asistencia de un yatiri o qulliri.

Las ofrendas destinadas al agua y a los achachilas, son entregadas fundamentalmente entre el "martes de challa" y el "domingo de tentación", durante la anata, las "cruces de mayo", la fiesta de los santos principales y en los ritos de siembra y propiciatorios de la lluvia. Los ingredientes de las "mesas" (o "misas") son: untu (sebo extraído del pecho de la llama), coa (Diplostephium cinereum), sullu (feto de llama), coca (Erithroxilum coca), copal (Bursera simaruba), quinua (Chenopodium quinoa) y azúcar (Girault 1988; Fernández 1995; Villagrán y Castro 2004). Además se emplean licores como el alcohol potable y el vino, siendo el primero de ellos el predilecto de los achachilas, y el segundo, de la Pachamama. El difunto yatiri Fortunato Manzano, contaba que hay un orden secuencial de las libaciones y ofrendas:

"Primero se pasa el alcohol en las cuatro esquinas, éste es del achachila. Luego, el vino que es de la Pachamama. Esta mesa es para achachilas, awichas, Pachamama y Santa la Marcota. La mesa se pasa por fuego, así se reciben ellos" (Fortunato Manzano 2010). ${ }^{25}$

La preparación de las ofrendas, la distribución de los ingredientes y el orden de entrega de estos alimentos a los comensales son diversos, y por lo general, están asociados a las vertientes culturales de los intermediarios que, en este caso, son los yatiris. Por ello, cada ceremonia varía, pues la inexistencia de yatiris estables en Socoroma ha obligado a recurrir a especialistas venidos desde Bolivia. La situación anterior exige la ejecución de permanentes esfuerzos por recordar la forma de cómo se realizaron las ceremonias en el pasado, informando al especialista acerca de las costumbres del pueblo. La entrega específica de ofrendas al agua es realizada en la limpia de canales en la semana de

\footnotetext{
${ }^{25}$ Santa la Marcota es también llamada Mama Cocha.
}

carnaval, por lo general entre el miércoles de ceniza y el primer Viernes Santo, y consiste en una "misa" (Girault 1988; Fernández 1995). Por otro lado, en las semanas previas a la siembra de maíz o papa, se realizan ofrendas simplificadas antes de iniciar la limpia de canales y bocatomas o en las chacras de los campesinos que tienen turnos de riego. Estas ofrendas simples consisten en el "pago" con coa, copal, hojas de coca, azúcar, alcohol y vino, que se disponen en la challa comunitaria. También es frecuente que algunas antiguas regadoras realicen ofrendas de vino tinto antes de iniciar el primer riego después de la siembra o del "guaneo"26 de la papa y maíz, pues requieren de un control muy exhaustivo del agua, ya que puede erosionar los suelos. Un testimonio da cuenta de esta situación:

"La señora Dominga cuando realiza su riego, se lleva un litro de vino y cuando comienza a llegar el agua, ella hace curar al agua para que le ayude en el riego, el vino le entrega en Aroma y como a un curadito le maneja al agua" (Eliana Choque Mamani, 55 años, 2010).

Adicionalmente, en el pasado, cuando las lluvias fueron escasas, los comuneros ofrecieron distintos tipos de sacrificios y súplicas en las vertientes y cerros, además de incrementar el despliegue ritual si las necesidades se volvían apremiantes, realizando para ello una serie de peregrinaciones a la costa o a los grandes lagos del altiplano, tal como lo realizaban las comunidades del occidente de Bolivia (Horkheimer 1990). Estos ritos son más elaborados y especializados, realizándose en períodos de sequía, cuando "los campesinos pueden recurrir a la ejecución de ritos especiales para obtener lluvia" (Van den Berg 1989: 68). Estos rituales no son nuevos en los Andes, pues han sido descritos por De Molina (1943 [1573]), De Murúa (1962 [1615]), Arriaga (1999 [1621]), Ramos Gavilán (1976 [1621]), De la Calancha (2004 [1638]) y Cobo (1956 [1653]). Además, Poma de Ayala, en su descripción de los trabajos del mes de noviembre menciona la existencia de ritos destinados a la obtención de agua en los períodos de escasez:

"Con caras de muerto, llorosos, caras de muerto, tiernos; Tus ninos de pecho; te imploran. Envíanos tu agua, tu lluvia a nosotros tus pobrecitos [...]. Deste manera llorando, pedían agua del cielo" (1992 [1613]: 1058).

\footnotetext{
${ }^{26}$ Fertilización de los cultivos con estiércol de pájaro y/u ovejas.
} 


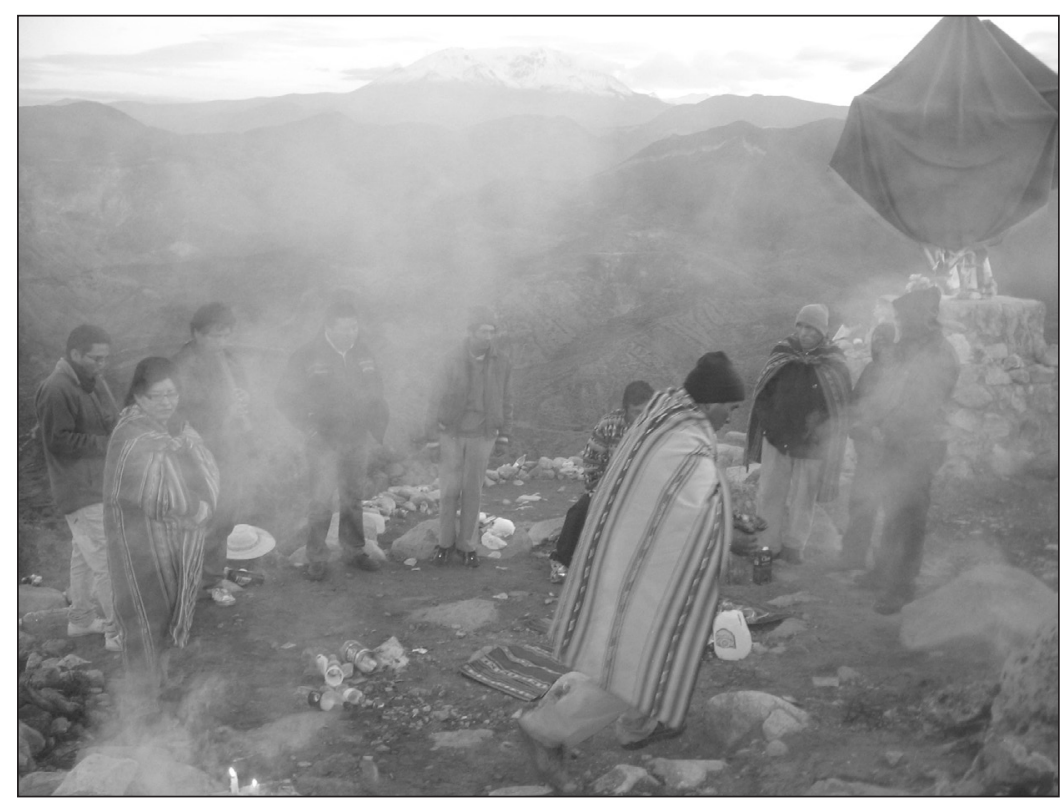

Figura 5. Ceremonia de Lluvia realizada en diciembre de 2010 en cerro Tata Calvario. Al fondo se observa el volcán Taapaca. Fotografía: Carlos Choque 2010.

Desde el s. XVI a la fecha los ritos destinados a la obtención de agua han simplificado sus ofrendas, además de sufrir algunas readecuaciones litúrgicas. No obstante, la finalidad y los destinatarios son los mismos, ya que sigue siendo un "rito de emergencia" (Rösing 1998: 408). En el verano de 2009, la señora Inocencia Sánchez informó que la última ceremonia comunitaria destinada a la obtención de agua fue realizada en las vertientes del pueblo entre los años 1970 y 1972, pues en ese período las precipitaciones fueron muy escasas y la situación fue agobiante para los cultivos:

"No había lluvia y mandamos una delegación para Arica a buscar agua de mar para la ceremonia. Harta gente participó, todos llevamos nuestras challas, los fabriqueros, los mayordomos, el juez de paz y la gente del pueblo, cada uno con su cariño. Fuimos al ojo de agua que está a la entrada del pueblo y ahí todos hemos hecho la tinka y la misa, de pronto nomás estábamos curados todos y de ahí nomás empezó a llover harto, harto. Eso me acuerdo, mucho hemos tomado con la Polonia y la Francisca. La gente antigua tenía esas costumbres" (Inocencia Sánchez, 92 años, 2010). ${ }^{27}$

\footnotetext{
${ }^{27}$ La tinka es una libación colectiva de alcohol realizada por los mayordomos de la iglesia y la comunidad.
}

Esta ceremonia tiene similitud con los ritos registrados por Vellard (1983), ya que consiste en el casamiento de las aguas del mar y las vertientes de Socoroma, lo cual ocurre en el mes de noviembre, intentando así asegurar las lluvias mediante súplicas ${ }^{28}$. En otras regiones de los Andes es común el intercambio de aguas de vertientes y lagunas, y en el caso de nuestra zona de estudio se usó el agua del mar, la cual según Polo de Ondegardo, fue reverenciada por los indios "y en especial los serranos que bajan a los llanos para diversos negocios adoran a la mar con diferentes cerimonias" (1916 [1567]: 191). Poma de Ayala, también se refirió a la Mama Cocha, como la madre mar, pues "aci lo más adorauan los Yungas y tenían sus ídolos junto a la mar" (1992 [1613]: 247). Este rito en los Andes posee variaciones, pero el aspecto central fue propiciar el casamiento y conflicto entre las dos aguas, originando las "nubes y la lluvia" (Albó 1974), la que debe ser acompañada de ritos libatorios y sacrificiales, movilizando de esta manera la fe y generando el autosacrificio de los socoromeños a sus achachilas, dueños de la lluvia (Figura 5).

\footnotetext{
${ }^{28}$ La realización de estos ritos es de suma importancia en los meses de noviembre y diciembre, pues las siembras ya se han realizado y las plantas presentan sus primeros brotes (Mamani 1988).
} 
Otro testimonio señala que a mediados de la década de 1980 se realizó la penúltima ceremonia para llamar a la lluvia, la cual fue llevada a cabo por solo algunos socoromeños que no superaron las diez personas. Se reunieron al alba en el Tata Calvario para realizar una wilancha ${ }^{29}$ para suplicar por agua al Señor del Calvario:

"No había lluvia, los animales estaban sufriendo y a las plantas estábamos regando con tarritos con agua para salvar la siembra, por eso fuimos al Calvario a realizar una ceremonia para el agua. Yo he regalado un cordero para la ceremonia al Señor, harta tinka hemos hecho. Pero un viejo nos gritó del pueblo diciendo: iestán brujeando la lluvia! Ese hombre ignorante, no sabe que tenemos que 'pagar' también por el agua" (Teófilo Choque, 87 años, 2010).

Ya en el s. XVII, De la Calancha se quejó de los sacrificios que se realizaban para obtener agua, asociando el rito a un acto demoníaco, pues el "demonio les decía que le sacrificacen muchos carneros, degollandolos en las mesmas faldas del cerro" (2004 [1638]: 1962). Su denuncia se asemeja a lo expuesto por el informante de Socoroma, repitiendo un mismo patrón, que consistió en la entrega de ofrendas y sacrificios para la obtención del agua.

Otro aspecto importante de los ritos para suplicar por agua fue el envío de 12 niños al Calvario, quienes debían girar de rodillas en torno a la apacheta, pidiendo por la llegada de las lluvias. En Socoroma este rito desapareció aproximadamente a comienzos de la década de 1950, manteniéndose por más tiempo en el altiplano con la sola diferencia del requerimiento de niños huérfanos, pues éstos son los que escucha Dios. Este mismo rito de emergencia que involucra a niños se practicó con frecuencia en el pueblo de Charaña (Bolivia) y en la estancia de Caparumiri a mediados de la década de 1960 , pues cuando hacía falta el agua, los mayordomos se vieron obligados a realizar los ritos de la lluvia, para no ser severamente criticados y hasta maldecidos por el pueblo, pues su descuido en los ciclos rituales era causante de la ausencia de lluvias, la muerte de los comuneros y el sufrimiento de las personas y animales, según relató el yatiri Fortunato Manzano. Evidencia similar reportó Rösing, en su estudio acerca de los ritos colectivos de los kallawayas, ya que mencionó "un tipo de wakayli en el que los niños juegan

\footnotetext{
${ }^{29}$ Sacrificio de un animal (cordero o camélido) con fines rituales.
}

un papel importante; se supone que sus súplicas al cielo nocturno han de mover la misericordia a los poderes de la lluvia" (1998: 421).

Además, podemos establecer con certeza que la Cruz de Milagro está directamente relacionada con el surgimiento de una vertiente de agua que escurre hacia el río Aroma, ya que ésta nace desde la cima del Tata Jiwata. De igual forma, es posible notar que desde las faldas del Vila Samanani, donde está ubicada la Cruz de Yapabelina, nace el río Zapahuira, el cual irriga parte de las estancias de Socoroma que se ubican al sur del pueblo principal, divisándose desde allí las estancias agrícolas de Murmuntane, Epispacha y Chusmiza; todas estas quebradas y sus afluentes forman parte de la hoya hidrográfica del río San José de Azapa. Asimismo, como ya hemos comentado, los santos principales están asociados a determinadas cruces, pero con atributos y significados complejos; así la Virgen del Rosario, llamada también en algunos ritos con el nombre aymara de Congorichava Awicha (abuela de las rodillas gastadas), es una representación de la Pachamama (Diez 2005), y San Francisco de Asís, que adquiere el nombre de Parkara Achachi (abuelo de frente pelada), representa al achachila principal del pueblo, el Tata Calvario.

También la Virgen de la Candelaria constituye una representación de los "espíritus de las cosechas o espíritus de la chacra" (Van den Berg 1989: 82), y por lo tanto, su rol es de invocación permanente del agua de los achachilas. Por otra parte, la imagen de Santa Bárbara (adscrita al altar de Santa Lucía), posee una función más protagónica en los ritos de lluvia que el resto de los santos principales, puesto que su cabeza está adornada con una gran corona de algodón que asemeja las nubes de lluvia y que no puede ser quitada porque puede provocar una "lluvia loca" sobre el pueblo. Asimismo, esta santa, según Van Kessel y Cutipa (1998) es una "divinidad chacarera", y una representación de la constelación de Wara wara, y por lo tanto, ligada a los ritos de observación de la naturaleza, permitiendo predecir la llegada de las lluvias y las heladas (Van den Berg 1989: 19).30

\footnotetext{
${ }^{30}$ Mamani (1988) señaló que los aymara realizan diferentes tipos de observaciones de las constelaciones y estrellas con la finalidad de prever riesgos, saber si ha de ser un año lluvioso o seco, de abundancia o escasez. En el caso de Socoroma estas observaciones se extienden desde el mes de junio en adelante, siendo las más importantes las que se realizan el 25 de diciembre, pues éstas
} 
En consecuencia, podemos asumir que existe una permanente relación e interacción entre el espacio sagrado y los habitantes de Socoroma, pues la abundancia de las cosechas y abastecimiento de agua dependieron de la continuidad de los ritos de lluvia, expresándose esto en la entrega "pagos" o dones a los achachilas. El incumplimiento de estos deberes implica la enfermedad de los hombres o el desastre agrícola, hecho que los socoromeños han tratado de evitar recurriendo a sus antiguas creencias y prácticas rituales. Esta situación se hizo manifiesta en diciembre del año 2010, pues las autoridades de la comunidad recurrieron nuevamente a los ritos de lluvia con la finalidad de asegurar la subsistencia de sus cultivos y animales, restableciendo así las reciprocidades con las fuerzas antinómicas y permitiendo el afloramiento de las antiguas memorias colectivas sobre este tipo de ritos, que pasan a tener un rol esencial entre los campesinos afectados por la sequía.

\section{^ Reflexiones en torno al agua y a los CERROS DE SOCOROMA}

La prolongada sequía que afectó a Socoroma, Belén y otras comunidades de la región entre los años 2003 y 2010, obligó a sus habitantes a retomar las ceremonias de súplica por el agua a los cerros sagrados de cada comunidad, intentando con ello restablecer los viejos vínculos y costumbres con el espacio sagrado, pues la inexistencia de lluvias en esos años fue visto como un castigo por haber dejado las antiguas "costumbres" y reciprocidades. En ese escenario, los comuneros consideraron que los seres humanos fueron creados por los achachilas, y en consecuencia, tienen la obligación de realizar "pagos" para lograr el equilibrio y armonía con los seres "extrahumanos", enfatizando además, que los antiguos comuneros acostumbraron a los achachilas a ser alimentados con misas, wilanchas y licores, estando ahora abandonados y hambrientos, convirtiéndose en muy peligrosos para los hombres. Asimismo, hemos mencionado que el agua es el principal recurso para la procreación y la mantención de la vida, una fuente esencial para la salud de los habitantes de los Andes, ya que cumple una función de purificación de los enfermos o de las personas que han sido atacadas por seres "extrahumanos".

determinarán si las lluvias serán profusas o escasas en los meses del verano estival.
Por lo tanto, los ritos destinados al mundo sagrado, y en particular al agua y a los cerros, fueron en el pasado fundamentales e imprescindibles en el ciclo agrícola; sin embargo, en Socoroma surgió una serie de rupturas en la vida ritual de la comunidad, originando pérdidas rituales que se expresaron en una discontinuidad y simplificación de las ceremonias dedicadas a los cerros. A su vez, los ritos reservados al agua se redujeron a súplicas de emergencia o ceremonias familiares. Un ejemplo de estas discontinuidades se observó en los ritos sacrificiales destinados al dueño de la vertiente de Capatiza, el que fue representado por un gran sapo conocido como "el patroncito", al que anualmente se le ofrecían wilanchas en el mes de junio, ceremonias que en los últimos 30 años no se han realizado, lo que ha vuelto el sector un área peligrosa para aquellas personas descuidadas o ignorantes del poder de este sapo olvidado.

En este escenario, nuestra propuesta acerca del principio de ruptura se basa en las transgresiones a las relaciones socioculturales y en las oposiciones a las normas que han regulado la entrega de los dones y reciprocidades, afectando así las expresiones de religiosidad de los habitantes de Socoroma. Debemos precisar que estas rupturas contemporáneas se originaron a partir de la instalación de la escuela pública, la que impartió nuevos valores culturales y sociales, impregnando a los jóvenes del pueblo de nuevas ideas y principios que ocasionaron una desnaturalización de sus creencias religiosas y pensamientos, que más tarde los llevaron a migrar a las ciudades de la costa, donde la intensificación de las relaciones sociales urbanas generaron nuevas interpretaciones de las realidades culturales. De esta manera se produjo un distanciamiento con su propia realidad religiosa precedente, que luego será heredada a las generaciones posteriores. La ausencia de interacción cultural y vida ritual necesariamente rompieron la continuidad de la vida religiosa, produciendo además diversas estrategias que encubrieron el olvido de las prácticas rituales y las magnitudes de las rupturas que habían tenido lugar, consintiendo una serie de reelaboraciones de las memorias de los ritos campesinos, y en consecuencia, modificaciones en su identidad.

La existencia de continuidades o tradiciones en los ritos agrícolas son expresados por aquellas poblaciones que no migraron a los centros urbanos, y si bien experimentaron las mismas impregnaciones valóricas y culturales inicia- 
les, éstas no han generado las transformaciones vistas en la población inmigrante, lo cual se debe en gran medida a la existencia de una regulación moral y cultural que es generada durante los ejercicios de memoria. Esta regulación ha sido ejercida y dirigida por "mayores" o ancianos, que ejecutan roles de fabriqueros y küjrarias, teniendo por misión salvaguardar la correcta ejecución de las tradiciones y costumbres, incentivando el cumplimiento de los thakhi de memoria y de las relaciones de reciprocidad con el espacio sagrado ${ }^{31}$. Igualmente, el propio paisaje ha ejercido su poder sobre las memorias de los sujetos que observan y reconocen en él las distintas fuerzas antinómicas desplegadas, que continúan ejerciendo sus poderes. Asimismo, las continuidades se han construido en el seno de la familia, pues es ahí donde se mantienen vivas las creencias y prácticas de los ritos que se transmiten en los encuentros familiares o en las propias festividades que poseen espacios de reelaboración de la memoria.

La coexistencia de las continuidades y rupturas entre la población socoromeña no debe ser vista como una manifestación ambigua, sino como un proceso de deconstrucción de sus ciclos rituales y de su propia identidad en los antiguos territorios costeros y serranos. Igualmente, debe precisarse que los cambios culturales generados por la modernidad y la globalización no solo se han limitado a la gestación del olvido o preservación de los ritos agrícolas, sino también a la existencia de múltiples interpretaciones y significados que deben ser comprendidos a partir de los límites temporales de la memoria y la conciencia colectiva de los socoromeños. Si bien todas las culturas mantienen su continuidad a partir de sus propios pensamientos, conductas y significados, no están exentas del proceso evolutivo. En este sentido, la vigencia de ciertos ritos agrícolas y pastoriles estará regida por sus propios procesos de cambios y rupturas que pueden haberse originado por diversos factores externos a su propia realidad.

\footnotetext{
${ }^{31}$ El rol de los "mayores", "la gente antigua" o los "ancianos", se ve también en los estudios de Albó y Ticona (1997). Al referirse al "thakhi comunal" o sistema de cargos en Santiago de Machaca, señalan la existencia de tres categorías, "el camino pequeño", "camino intermedio" y el "camino grande", que se expresan en un lapso de 20 años de servicio a la comunidad en cargos tradicionales y religiosos. Una vez cumplidos los tres caminos, las autoridades ingresaban a una nueva categoría de "pasado", que los convertía en "los más escuchados y los primeros invitados siempre que hay celebraciones" (1997: 85).
}

En este contexto, las memorias de la religiosidad de los socoromeños de origen campesino e inmigrante logran acercamientos y convergencias mediante el rol mediador de los "mayores" o "ancianos" del pueblo, generando con ello las reafirmaciones de la identidad y diversas resistencias a la "pérdida ritual". Así, el culto al agua y a los cerros adquiere un rol gravitante en cuanto a la preservación de la identidad, ya que los ritos cumplen un rol mediador entre las antiguas y nuevas memorias de identidad colectiva.

El actual culto a los cerros debe ser comprendido como una "celebración de cosecha" que refuerza los lazos de identidad, revitalizando los vínculos rituales en la comunidad. Ejemplo de esto son las peregrinaciones a los distantes cerros sagrados, ya que son una forma de autosacrificio que permite redimir los pecados y agradecer por las cosechas obtenidas y el agua recibida. Estas peregrinaciones a los cerros Tata Jiwata y Vila Samanani generan entre los socoromeños expresiones de fe y fervor sentimental, alcanzando su punto culminante cuando saludan a la apacheta, realizando tres rondas de rodillas para, finalmente, entregar las ofrendas rituales a los achachilas, restableciendo así los vínculos rituales. De manera similar los ritos propiciatorios del agua tienen como fin asegurar la llegada de las ansiadas lluvias, haciendo converger las energías y exigencias de una máxima religiosidad, pues se lucha contra lo imposible, requiriendo de sentimientos colectivos de entrega y devoción, que solo culminan cuando los comuneros expresan felicidad y alegría por los deberes cumplidos al terminar los ritos sacrificiales y las libaciones comunitarias.

Considerando las rupturas en la religiosidad de los socoromeños, es posible comprender por qué no existe una advocación explícita o directa a los achachilas regionales como el Taapaca o el Tacora (Reinhard 2002) ${ }^{32}$, y menos aún a otros más lejanos como el Illimani, el Illampu o el Wayna Potosí, que no solo se destacan por su altura y belleza, sino por el poder que ostentan, al ser los verdaderos dueños de las lluvias. Sin embargo, las continuidades

\footnotetext{
32 Reinhard (2002) identificó dentro de las evidencias materiales encontradas en el Taapaca un recinto ceremonial en el noroeste del volcán, además de restos materiales de fibra, cerámica y una estatuilla realizada en mullu (Spondylus princeps) en perfecto estado, hecho que indicaría el rol sagrado de esta cumbre para la población indígena prehispánica de Socoroma.
} 
que construyen los campesinos de Socoroma permiten la permanencia de ciertos ritos al agua y a los cerros, pues las ofrendas entregadas a los achachilas Tata Calvario, Yapabelina y Tata Jiwata, terminan siendo entregados finalmente a los achachilas regionales, pues cada cerro sagrado de la comunidad o de la región acaba participando del poder otorgado por las grandes cumbres y volcanes surandinos. En el caso de los cerros locales de la costa, según el yatiri Fortunato Manzano, se producían las mismas vinculaciones y reciprocidades entre el Morro de Arica, el Taapaca y el volcán Tacora, que son apreciados desde los cerros de Arica o sus valles costeros.

Las relaciones jerárquicas entre los achachilas no solo se expresan en el ámbito ritual, ya que también pudieron contener significados políticos en los Andes antes de la conquista hispana, pues tanto los antecedentes mitohistóricos como las concepciones actuales indican que los cerros poseen distintas jerarquías, lo cual permite generar reciprocidades y asistencias en sus guerras míticas. Esto implica que en la actualidad el culto a los cerros locales de Socoroma involucra la existencia de jerarquías y prestigios que son aprovechados por los vecinos para reafirmar y elevar su estima en la provincia y en la propia comunidad, legitimando las diferencias de riquezas y el poder simbólico ante otros "comuneros". Este respeto social se construye durante la realización de las peregrinaciones a los distintos cerros sagrados, como también por la búsqueda de prestigio, motivando una competencia entre los diferentes "pasantes" o "alféreces", que buscan realizar cada vez mejores fiestas y peregrinaciones, reafirmando así la identidad de sus linajes y su asociación con los cerros locales. Esto puede entenderse como la permanente necesidad de diferenciación con los "otros", generando así una distinción de valores y una unión indisoluble entre peregrinos y cerros sagrados, una práctica que se reproduce generacionalmente con idénticos procesos y ritos.

Finalmente, solo nos resta agregar que la deconstrucción de la identidad actual de Socoroma y las comunidades andinas de los altos de Arica es producto de las rupturas y continuidades de sus ritos agrícolas. La reproducción de los ritos religiosos, los cultos a los cerros y los amtañ thakhi (caminos de memoria), son parte esencial de su existencia, pues han permitido la reelaboración de sus orígenes mitológicos y costumbres, reafirmando las identidades colectivas y familiares en el s. XXI; permitiendo además, que los ritos agrícolas se conserven en el imaginario colectivo de los socoromeños, tanto por su relación de producción como por sus significados socioculturales. Todo ello permite la continuidad de los vínculos comunitarios y rituales en un período de cambios culturales, políticos y económicos que van transformando velozmente los Andes.

Agradecimientos Este trabajo ha sido elaborado en el marco de la Beca Huiracocha 2010 otorgada por la Pontificia Universidad Católica del Perú y el proyecto FONDECYT 1100060 otorgado a uno de los autores, mediante la investigación doctoral denominada "Se van los peruanos... los más testarudos se quedan: Memorias de la 'chilenización' en Socoroma". Además, agradecemos a un grupo de colegas y evaluadores por sus comentarios y sugerencias que permitieron mejorar este escrito. Asimismo, agradecemos a los vecinos de Socoroma y al difunto yatiri Fortunato Manzano, por su incalculable aporte para reconocer el culto al agua y los cerros en la actualidad.

\section{* Referencias citadas}

ABERCROMBIE, T., 2006. Caminos de la memoria y del poder. Editorial IFEA-IEB-ASDI, La Paz.

AGUIRRE, C. y C. MONDACA, 2011. Estado nacional y comunidad andina. Disciplinamiento y articulación social en Arica, 1880-1929. Revista de Historia 44 (1): 5-50.

ALAEZ, A., 2001. Duelo andino: Sabiduría y elaboración de la muerte en los rituales mortuorios. Chungara 33 (2): 173-178.
ALBÓ, X., 1974. Santa Vera Cruz Tatita. Allpanchis Phuturinka VII: 163-216.

1992. La experiencia religiosa aymara. En Rostros indios de Dios, M. Marzal (Ed.), pp. 205-265. Ediciones CIPCA-Hisbol-UCB, La Paz.

1999. Iguales aunque diferentes. UNICEF-CIPCA, La Paz. 
ALBÓ, X. y E. TICONA, 1997. Jesús de Machaqa: La marka rebelde. La lucha por el poder comunal. CIPCA, CEDOIN, La Paz.

ARRIAGA, J., 1999 [1621]. La extirpación de la idolatría en el Pirú. Centro Bartolomé de Las Casas, Cusco.

ARTEAGA, A. y J. DOMIC, 2007. Ser wawa en los Andes: Representación social de mujeres migrantes aymara sobre el niño(a) aymara. RevistaAjayu V (1): 1-26.

BARTH, F., 1976. Los grupos étnicos y sus fronteras. Fondo de Cultura Económica, México D.F.

BOUYSSE-CASSAGNE, T. y O. HARRIS, 1987. Pacha: En torno al pensamiento aymara. En Tres reflexiones sobre el pensamiento andino, T. Bouysse-Cassagne (Ed.), pp. 11-59. Hisbol, La Paz.

BRAH, A., 1996. Cartographies of diaspora: Contesting identities. Gender, racism, ethnicity. Routledge, Londres.

CHOQUE, C., 2009a. Memoria y olvido de Socoroma. Ediciones Tierra Viva, Arica.

2009b. Divergencias y antagonismos del movimiento social indígena en la región de Arica y Parinacota (1965-1985). Confluenze 1 (2): 267-289.

COBO, B., 1956 [1653]. Historia del nuevo mundo. Biblioteca de Autores Españoles, Madrid.

DE LA CALANCHA, A., 2004 [1638]. Crónica moralizada de la Orden de San Agustín en el Perú con sucesos ejemplares en esta monarquía. Archivo BNB, Sucre.

DE MOLINA, C., 1943 [1573]. Relación de las fábulas y ritos de los incas. Los Pequeños Grandes Libros de Historia Americana, Serie 1, $\mathrm{n}^{\circ} 4$, Lima.

DE MURÚA, M., 1962 [1615]. Historia general del Perú: Origen y descendencia de los incas. Editorial Manuel Ballesteros, Madrid.

DIEZ, A., 2005. Los sistemas de cargos religiosos y sus transformaciones. En Religiones andinas, M. Marzal (Ed.), pp. 253-286. Editorial Trotta, Madrid.

EMBER, C., M. EMBER y M. PEREGRINE, 2006. Discovering anthropology: Researchers at work-physical anthropology and archaeo$\log y$. Pearson-Prentice Hall, México D.F.

ESPINOSA, G., 1996. Lari y Jamp'atu. Ritual de lluvia y simbolismo andino en una escena de arte rupestre de Ariquilda 1, norte de Chile. Chungara 28 (1): 133-157.
ESPINOZA, W., 1987. Los incas: Economía, sociedad y Estado en la era del Tahuantinsuyo. Ediciones Amaru, Lima.

FERNÁNDEZ, G., 1995. El banquete aymara: Mesas y yatiris. Hisbol, La Paz.

GIL, F. y G. FERNÁNDEZ, 2008. El culto a los cerros en el mundo andino. Revista Española de Antropología Americana 38 (1): 105-113.

GIRAULT, L., 1988. Rituales en las regiones andinas de Bolivia y Perú. Ediciones CERES-MUSEF-QUIPUS, La Paz.

GISBERT, T., 1980. Iconografía y mitos indígenas en el arte. Gisbert \& Cía. S.A., La Paz.

GONZÁLEZ, H., 1997. Apuntes sobre el tema de la identidad cultural en la región de Tarapacá. Estudios Atacameños 13: 27-45.

GUNDERMANN, H., 2000. Las organizaciones étnicas y el discurso de la etnicidad en el norte de Chile, 1980-200o. Estudios Atacameños 19: 75-91.

2004. Sociedades andinas, municipio y etnicidad; la transformación de los espacios políticos locales andinos en Chile. En Los desafios de la interculturalidad, identidad, politica y derecho, M. Castro (Ed.), pp. 291-328. Universidad de Chile, Santiago.

2005. Comunidad aymara y conflicto interno sobre la tierra en la región de Tarapacá, Chile. Cuadernos Interculturales 3 (5): 43-66.

GUTMANN, M., 1993. Visión andina del mundo y conceptos religiosos en cuentos orales quechuas del Perú. En Mito y simbolismo en los Andes. La figura y la palabra, E. Urbano (Ed.), pp. 239-258. Centro de Estudios Regionales Andinos, Cusco.

HALL, S., 1990. Cultural identity and diaspora. En Identity: Community, culture, difference, J. Rutherford (Ed.), pp. 222-237. Lawrence \& Wishart, Londres.

HORKHEIMER, H., 1990. Alimentación y obtención de alimentos en los Andes prehispánicos. Hisbol, La Paz.

JORDA, E., 1981. La cosmovisión aymara en el diálogo de la fe: Teología desde el lago Titicaca. Tesis doctoral. Pontificia Universidad Católica del Perú, Lima.

KRIEGER, P., 2004. La deconstrucción de Jacques Derrida (19302004). Anales del Instituto de Investigaciones Estéticas 84: 179-188.

LACLAU, E., 1993. Nuevas reflexiones sobre la revolución de nuestro tiempo. Nueva Visión, Buenos Aires. 
LEONI, J., 2005. La veneración de las montañas en los Andes preincaicos: El caso de Nawinpukyo (Ayacucho, Perú) en el período Intermedio Temprano. Chungara, Revista de Antropología Chilena 37 (2): 151-164.

LOZADA, B., 2003. Ritos andinos y concepción del mundo. Estudios Bolivianos 8: 1-18.

MAMANI, M., 1988. Agricultura a los 4000 metros. En Raíces de América: El mundo aymara, X. Albó (Ed.), pp. 75-128. Editorial Alianza América-UNESCO, Barcelona.

2002. El rito agrícola de Pachallampi y la música en Pachamama, precordillera de Parinacota. Revista Musical Chilena 198: 45-62.

MARTÍNEZ, G., 1983. Los dioses de los cerros en los Andes. Journal de la Societé des Américanistes 69: 85-115.

2009. Humor y sacralidad en el mundo autóctono andino. Chungara, Revista de Antropología Chilena 41 (2): 275-286.

MARZAL, M., 1992. La experiencia religiosa quechua. En Rostros indios de Dios, M. Marzal (Ed.), pp. 27-80. CIPCA, La Paz.

MIGNONE, P., 2010. Ritualidad estatal, capacocha y actores sociales locales. El cementerio del volcán Llullaillaco. Estudios Atacameños, Arqueología y Antropología Surandinas 40: 43-62.

MONTES, F., 1987. La máscara de piedra. Ediciones Armonía, La Paz.

MOYANO, R., 2009. El adoratorio del cerro El Potro: Arqueología de alta montaña en la cordillera de Copiapó, norte de Chile. Estudios Atacameños, Arqueología y Antropología Surandinas 38:39-54.

MUÑOZ, I. y J. CHACAMA, 2006. Complejidad social en las alturas de Arica: Territorio, etnicidad y vinculación con el Estado inca. Universidad de Tarapacá, Arica.

PALACIOS, R., 1974. La chilenización de Tacna y Arica, 1883-1929. Editorial Arica, Lima.

POLO DE ONDEGARDO, J., 1916 [1567]. Informaciones acerca de la religión y gobierno de los incas por el licenciado Polo de Ondegardo. Ediciones Sanmartí y Cía., Lima.

POMA DE AYALA, G., 1992 [1613]. Nueva corónica y buen gobierno. Siglo XXI, México D.F.

POOLE, D., 1982. Los santuarios religiosos en la economía regional andina (Cusco).Allpanchis Phuturinka 16 (19): 79-116.

PULGAR VIDAL, J., 1940. Las ocho regiones naturales del Perú. Tercera Asamblea del Instituto Panamericano de Geografía e Historia, La Habana.
RAMOS GAVILÁN, A., 1976 [1621]. Historia de nuestra Señora de Copacabana. Academia Boliviana de Historia, La Paz.

REINHARD, J., 2002. A high altitude archaeological survey in Northern Chile. Chungara 34 (1): 85-99.

RIVIÈRE, G., 1979. Intercambio y reciprocidad en Carangas. Antropología 1: 85-113.

RÖSING, I., 1998. Rituales para llamar la lluvia. Los Amigos del Libro, Cochabamba.

ROSTWOROWSKI, M., 200o. Estructuras andinas del poder: Ideología religiosa y política. Instituto de Estudios Peruanos (IEP), Lima.

SHARON, D., 2004. El chamán de los cuatro vientos. Siglo XXI, México D.F.

SANHUEZA, C., 2008. Territorios, prácticas rituales y demarcación del espacio en Tarapacá en el siglo XVI. Boletín del Museo Chileno de Arte Precolombino 13 (2): 57-75.

SERRACINO, G.y R. STEHBERG, 1975. Vida pastoril en la precordillera andina (Guatin, San Pedro de Atacama, Chile). Estudios Atacameños 3: 73-88.

SIGL, E., 2009. Donde papas y diablos bailan. Danza, producción agrícola y religión en el altiplano boliviano. Maguare 23: 303-341.

VAN DEN BERG, H., 1989. La Tierra no da así no más. Editorial CEDLA, Amsterdam.

VAN KESSEL, J., 2001. El ritual mortuorio de los aymara de Tarapacá como vivencia y crianza de la vida. Chungara 33 (2): 221-234.

2003a. Holocausto al progreso: Los aymara de Tarapacá. Ediciones IECTA, Iquique.

2003b. La economía andina de crianza; actores y factores meta-económicos. Revista de Ciencias Sociales 13: 71-78.

VAN KESSEL, J. y G. CUTIPA, 1998. El Marani de Chipukuni. Editorial IECTA-CIDSA, Iquique.

VELLARD, J. 1983. La medicina indígena sudamericana. Revista de la Facultad de Filosofía y Letras, Universidad de Buenos Aires s/ño : 5-23

VILLAGRÁN, C. y V. CASTRO, 2004. Ciencia indígena de los Andes del norte de Chile. Editorial Universitaria, Santiago. 
WISSLER, H., 2010. Q'ero, Perú: La regeneración de relaciones cosmológicas e identidades específicas a través de la música. Revista Antropológica XXVIII (28): 93-116.
ZAPATA, C., 2007. Memoria e historia. El proyecto de una identidad colectiva entre los aymara de Chile. Chungara, Revista de Antropología Chilena 39 (2): 171-183. 